\title{
An Evaluation of Er:YAG Laser in an Intact Enamel Treatment on Bonding to the Resin Cement Compared to Four Traditional Techniques
}

\author{
Yara Mohammad ${ }^{1}$, Oula Yassin² ${ }^{2}$ Louis Hardan ${ }^{3}$, Omar Hamadah $^{4}$, Mohammad Tamer Abbara ${ }^{5}$
}

\begin{abstract}
Aim of study: Evaluation of the bond strength of the resin cement after enamel conditioning with erbium-doped yttrium aluminum garnet laser compared to other four different techniques.

Materials and methods: The study consisted of 50 enamel specimens excluded from the smooth surfaces of newly extracted human 3 rd molars. The specimens were randomly divided into five groups in terms of the enamel treatment technique. Each group $(n=10)$ was conditioned differently by bevel and acid etching group (I), acid etching technique group (II), double acid etching technique group (III), air abrasion followed by acid etching group (IV), and Er:YAG laser followed by acid etching group (V). After enamel treatment, a resin cylinder was installed using split Teflon matrix on each enamel specimen. Then the specimens were exposed to a shear strength device, and shear force was applied. The results were recorded with Newton. The required data were collected and statistically analyzed. A one-way ANOVA test was conducted to compare the five study groups using SPSS version $21(p<0.05)$.

Results: All groups showed high shear bond strength values ranging from $19.26 \mathrm{MPa}$ (for group III) to $27.05 \mathrm{MPa}$ (for group V). The enamel treatment with Er:YAG laser followed by acid etching gave the best results with significant differences compared to the other groups.

Conclusion: Within the limitations of the present study, it can be concluded that the combination between the Er:YAG laser and the acid etching enhances the bond strength of resin cement with the enamel.

Clinical significance: The use of Er:YAG laser followed by acid etching can be a successful technique for enamel conditioning and the results showed their superiority over the other groups.

Keywords: Acid etching, Air abrasion, Enamel treatment, Er:YAG laser.

The Journal of Contemporary Dental Practice (2019): 10.5005/jp-journals-10024-2647
\end{abstract}

\section{INTRODUCTION}

Bonding of the resin cement mainly relies on the mechanical penetration of adhesive systems to irregularities in the enamel surface caused by a prior enamel etching. Acid etching has been the conventional technique of enamel conditioning since 1955. ${ }^{1,2}$ The mechanism of enamel acid etching is based on hydroxyapatite eroding, which facilitates penetration by the production of resin tags. $^{3}$

Some authors suggested that air abrasion may be used instead of acid etching because of its ability to increase enamel surface roughness. It has been noted that a combination of chemical acid etching and mechanical air abrasion may be more effective than only acid etching in increasing retention and preventing micro leakage. $^{4}$

Presently, there are many techniques that can be used to support dental surface conditioning such as the erbiumdoped yttrium aluminum garnet (Er:YAG) laser. ${ }^{5}$ It has been studied as an alternative method to remove oral mineralized tissues for restorative goals. ${ }^{6}$ Hard dental tissue removal by Er:YAG laser hangs on the light energy absorbed by the water and hydroxyapatite existing in the enamel, which have a high absorption coefficient close to $2.94 \mu \mathrm{m} .^{7}$ Er:YAG laser can selectively remove hydroxyapatite crystals present on the enamel surface when it is used at suitable doses, thus resulting in an irregular surface pattern that could promote the micromechanical retention of adhesive agents to the enamel. ${ }^{8}$
1,2,5 Department of Endodontics and Restorative Dentistry, University of Damascus Dental School, Syrian Arab Republic

${ }^{3}$ Department of Restorative and Esthetic Dentistry, Faculty of Dental Medicine, St Joseph University, Beirut, Lebanon

${ }^{4}$ Oral Medicine Department, University of Damascus Dental School, Syrian Arab Republic

Corresponding Author:Yara Mohammad, Department of Endodontics and Restorative Dentistry, University of Damascus Dental School, Syrian Arab Republic, Phone: +963 933551425, e-mail: yara.mhd.17@ gmail.com

How to cite this article: Mohammad Y, Yassin O, et al. An Evaluation of Er:YAG Laser in an Intact Enamel Treatment on Bonding to the Resin Cement Compared to Four Traditional Techniques. J Contemp Dent Pract 2019;20(9):1014-1018.

Source of support: Damascus University

Conflict of interest: None

The concept of "laser etching" is still developing in dental practice. If laser performs the functions of acid etching and produces a typical bonding surface for a restorative material, it may be an appropriate alternative to acid etching. ${ }^{9}$ Er:YAG laser-exposed surfaces are resistant to acids as a result of its ability to modify the calcium-to-phosphorus ratio, decrease the amount of water and organic components, and lead to low acid-soluble compounds; therefore, it could prevent acid attacks 
and dental caries, mainly around the orthodontic brackets and attachments. ${ }^{10,11}$

The effects of alumina air abrasion and Er:YAG laser irradiation as alternatives to acid etching for enamel conditioning are still controversial.

The aim of this study was to compare the effects of different enamel conditioning methods on the shear bond strength between the resin cement and the enamel.

\section{Materials and Methods}

The protocol of this study was approved by the research ethics committee of Damascus University (ethical approval no. 2086, date: 8/2017). The study consisted of 50 enamel specimens, excluded from the smooth (buccal, lingual, and palatal) surfaces of newly extracted human 3rd molars for orthodontic reasons regardless of the patient's age. It has been selected to verify the following conditions: free of caries, cracks, and fractures after examination under magnification. These samples were randomly divided into five groups. Each group included 10 enamel specimens and was treated with a different method-group I: (control group) bevel and acid etching, group II: acid etching, group III: double acid etching, group IV: air abrasion using aluminum oxide particles followed by acid etching, and group V: Er:YAG followed by acid etching.

The teeth were soaked in a $5.25 \%$ sodium hypochlorite solution for a minute to dissolve the organic debris. Next, they were saved in the saline until used. The enamel surfaces were cleaned using the cleaning paste and a rubber cup with a low-speed hand piece. Then the teeth were washed with water and dried by air.

The roots of the teeth were separated using a diamond disc (Horico ${ }^{\oplus}$, Berlin, Germany). The crowns were fixed using wax in plastic molds to make acrylic molds for the specimens corresponding to the place where to be installed on a shear bond device (TesT ${ }^{\oplus}, \mathrm{GmbH}$, Germany) (Fig. 1).

\section{Enamel Treatment}

\section{Group I: (Control Group) Bevel and Acid Etching}

The enamel surfaces were beveled by conical diamond bur $0.5 \mathrm{~mm}$ (Jota, Switzerland). After that, the Eco-Etch ${ }^{\circledR}$ gel $37 \%$ phosphoric acid (Ivoclar Vivadent ${ }^{\oplus}$, Schaan, Liechtenstein) was applied for 30 seconds. Then they were washed for 15 seconds and completely dried using an air stream until seeing the frosty appearance (etching process) (Fig. 2A).

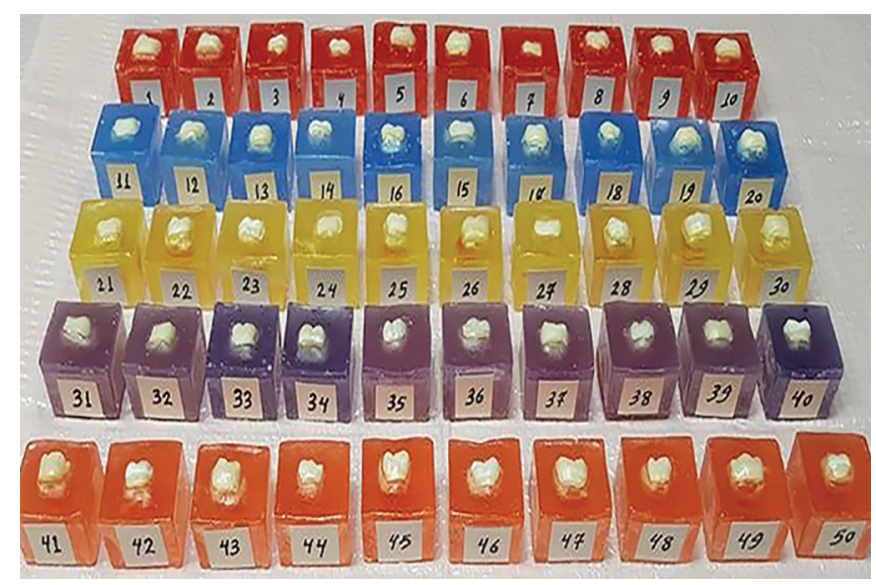

Fig. 1: Sample of the study

\section{Group II: Acid Etching}

Eco-Etch ${ }^{\circledast}$ gel $37 \%$ phosphoric acid (Ivoclar Vivadent ${ }^{\circledR}$, Schaan, Liechtenstein) was applied on the enamel surfaces for 30 seconds. Then they were washed for 15 seconds and completely dried using an air stream until seeing the frosty appearance (etching process).

\section{Group III: Double Acid Etching}

Etching process was done twice; so the full exposure time for phosphoric acid was 60 seconds ( 30 seconds in each one). ${ }^{12}$

\section{Group IV: Air Abrasion Followed by Acid Etching}

The air abrasion (Rondoflex ${ }^{\circledR}$ plus Air Abrasion, Germany) was applied using $50 \mu$ aluminum oxide particles on the enamel surfaces with a pressure of 80 psi for 10 seconds, $10 \mathrm{~mm}$ from the enamel surface, and at a $90^{\circ}$ angle. After that, they were washed for 15 seconds, and the complete drying was done with an air stream, then the etching process was applied. ${ }^{13}$

\section{Group V: Er:YAG Followed by Acid Etching}

The enamel surfaces were exposed to the Er:YAG laser (Fotona ${ }^{\circledR}$, Light Walker, USA) for 10 seconds using the following parameters (a wavelength of $2.94 \mu \mathrm{m}$, short pulses of 10 pulses per second, a pulse time of 180 microseconds, and a $300 \mathrm{~mJ}$ input power per pulse with a water cooling of 5 milliliters per minute) by the R02-C hand piece (Fotona ${ }^{\circledast}$, LightWalker, USA) without contact to the enamel surface, with a diameter of $0.9 \mathrm{~mm}$ package and $1 \mathrm{~mm}$ away from the enamel surface and a vertical scanner movement on the surface. ${ }^{14}$ After application of the laser, they were washed and dried; then the etching process was applied (Fig. 3).

\section{Bonding and Applying Resin Cylinders}

The fifth-generation bond Tetric N-bond ${ }^{\circledR}$ (Ivoclar Vivadent ${ }^{\oplus}$, Liechtenstien) was applied to the enamel surfaces with a micro brush, and the bonding agent was exposed to an LED curing light for 20 seconds as close as possible to the enamel surface according to the manufacturer's instructions (Fig. 2B). The split Teflon matrix with a cylindrical shape of $3 \mathrm{~mm}$ diameter and $2 \mathrm{~mm}$ height on the enamel surfaces were installed on the enamel surfaces using condensation silicone to prevent movement while adding the resin cement (Fig. 2C).

Then the resin cement Variolink- ${ }^{\circledR}$ (ivoclar Vivadent ${ }^{\circledR}$, Liechtenstien) was applied and cured by an LED curing light for 30 seconds as close as possible to the split Teflon matrix (Fig. 2D).

\section{Thermal Cycles and Application of Shear Bond Strength}

After applying the resin cylinders, all specimens were subjected to the thermal cycles in two water incubators (Memmert ${ }^{\mathrm{TM}}, \mathrm{GmbH}$, Germany), in which the temperature of the first was set at $5^{\circ} \mathrm{C}$, while the temperature of the second was $55^{\circ} \mathrm{C}$. The specimens were immersed in each water incubator for 30 seconds, with a transition period of 5 seconds. This process was repeated 200 times to achieve 200 thermal cycles. ${ }^{15}$

Then, they were subjected to a shear bond strength device (TesT ${ }^{\oplus}, \mathrm{GmbH}$, Germany), where the head of the device was applied on an 1-mm area with a loading speed of $1 \mathrm{~mm}$ per second to record the shear bond strength required for the separation of the resin cylinders from the enamel surfaces (Fig. 4). The shear strength was recorded with Newton and the electronic diagrams were stored for all specimens. 


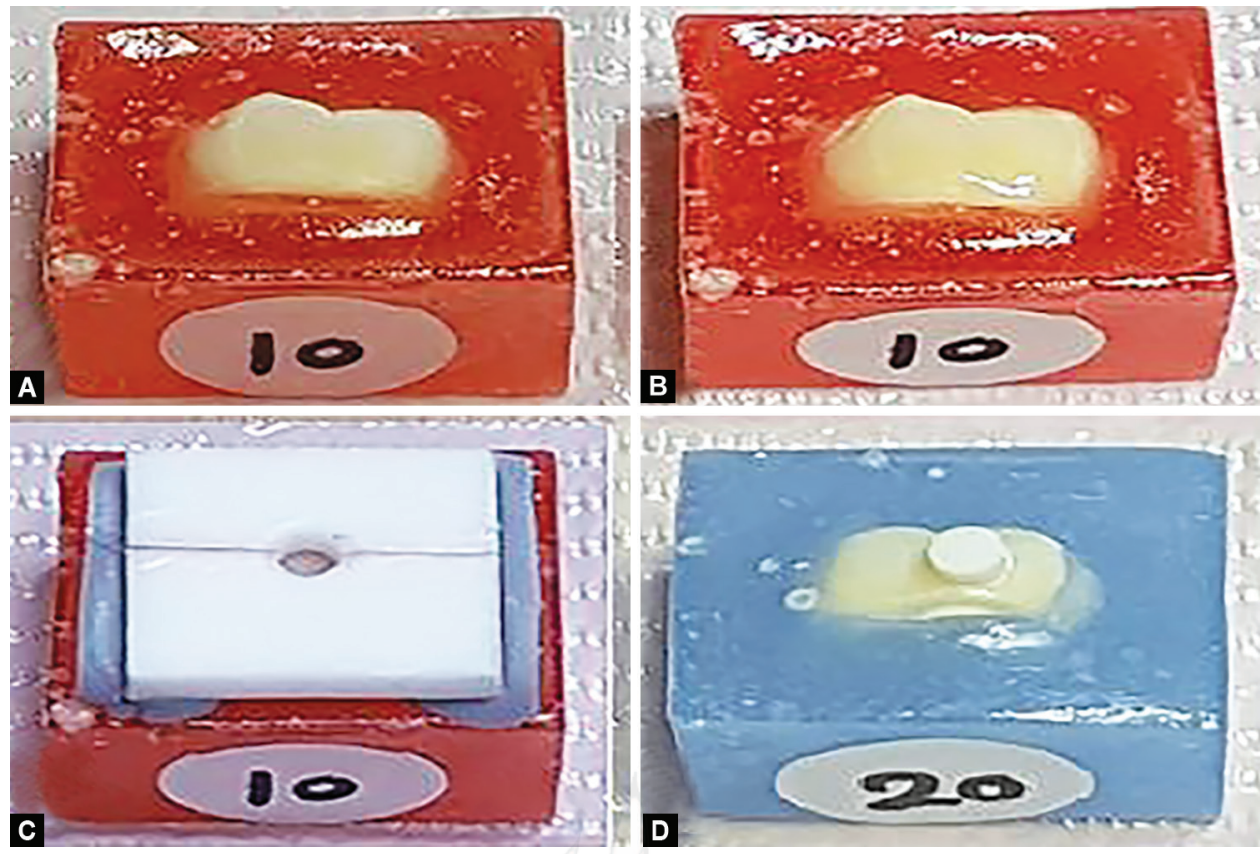

Figs 2A to D: (A) A specimen after etching; (B) Applying bonding agent; (C) A split Teflon matrix fixed on the enamel surface with condensation silicon; (D) Applying resin cement

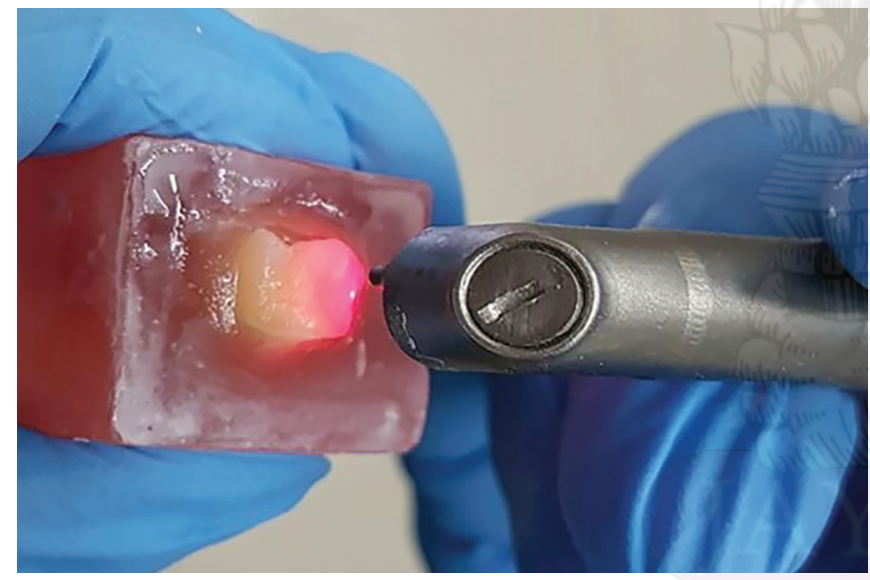

Fig. 3: Exposing to Er:YAG laser with R02-C hand piece without contact (Fotona ${ }^{\oplus}$, LightWalker, USA)

\section{Statistical Analysis}

Statistical analysis was performed using SPSS ${ }^{\circledR}$ version $21\left(\right.$ IBM $^{\circledR}$ SPSS, USA). A one-way ANOVA test was used to detect significant differences between the compared groups $(p<0.05)$, and LSD analysis was used to investigate binary comparisons between the study groups.

\section{Results}

Descriptive statistics of the studied groups ( $n=50$ with 10 in each group) and one-way ANOVA results are given in Table 1.

In general, the highest mean value of shear bond strength was observed in the group V Er:YAG followed by acid etching (27.05 $\mathrm{MPa}$ ), whereas the lowest was in the group III double acid etching (19.26 MPa) (Fig. 5). There were statistically significant differences between the study groups according to the one-way ANOVA result $(p<0.05)$. Moreover, the differences observed in the group $V$ were

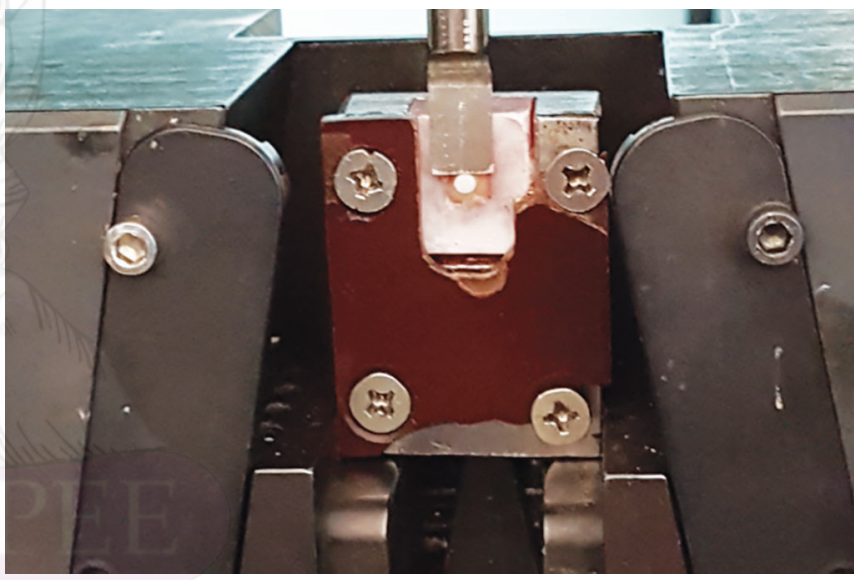

Fig. 4: Exposing to the shear bond device (Tes $\mathrm{T}^{\oplus}, \mathrm{GmbH}$, Germany)

statistically significant compared to other groups $(p<0.05)$ by LSD analysis (Table 2).

\section{Discussion}

Recently, several reports have been published in the dental literature encouraging the bonding of conservative cosmetic veneers to non-prepared enamel, after etching with $37 \%$ phosphoric acid at different times. ${ }^{16,17}$ Owing to the nature of the superficial enamel and its high content of minerals and fluoride, the idea of this study was to evaluate its ability to bond with the resin cement used for bonding ceramic veneers after enamel treatment by five different techniques.

Bonding of resin cement depends on the enamel conditioning, which has become an essential step prior to the bonding procedures. The dentist applies this step to remove the smear layer attached to the tooth and create microscopic gaps on the 
Table 1: Descriptive statistics of the studied groups ( $n=50$ with 10 enamel surface in each group) and one-way ANOVA result

\begin{tabular}{llllllll}
\hline \multirow{2}{*}{$\begin{array}{l}\text { Enamel treatment } \\
\text { technique }\end{array}$} & \multicolumn{7}{c}{ Shear bond strength on enamel (MPa) } \\
\cline { 2 - 6 } & Mean & SE mean* & SD & Min & Max & fvalue & pvalue \\
\hline Group I & 22.96 & 1.36 & 4.30 & 16.7 & 31.79 & 4.484 & 0.004 \\
Group II & 21.04 & 1.10 & 3.49 & 16.15 & 26.07 & & \\
Group III & 19.26 & 1.26 & 4.00 & 14.01 & 25.71 & \\
Group IV & 22.04 & 0.78 & 2.46 & 18.45 & 25.54 & \\
Group V & 27.05 & 2.03 & 6.42 & 20.25 & 41.11 & & \\
\hline
\end{tabular}

*SE, standard error of the mean; SD, standard deviation; Min, minimum value; Max, maximum value; $p$ value $0.004<0.05$ employing one-way ANOVA

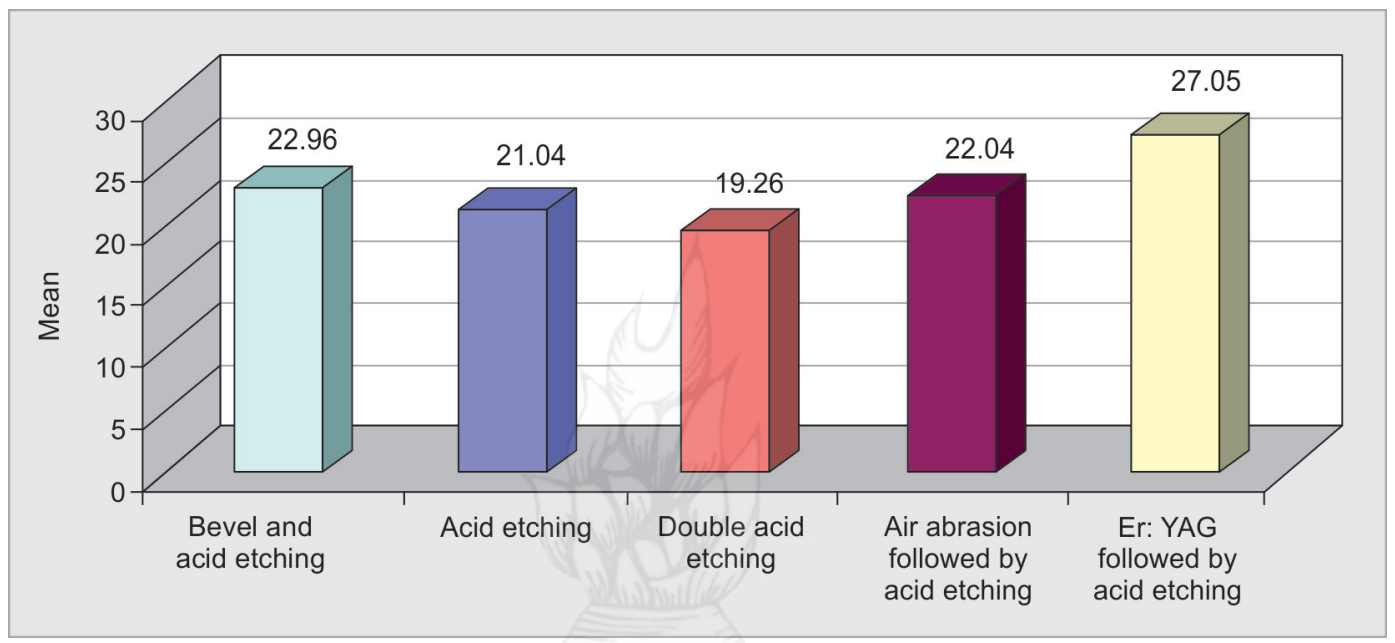

Fig. 5: The mean bond strength of resin cement to intact enamel (MPa) according to enamel treatment techniques

Table 2: LSD analysis for binary comparisons of the study groups

\begin{tabular}{llcl}
\hline Group (I) & Group (J) & Mean difference (I-J) & p value \\
\hline Group I & Group II & 1.92 & 0.326 \\
& Group III & 3.70 & 0.063 \\
& Group IV & 0.93 & 0.635 \\
Group II & Group V & -4.08 & 0.041 \\
& Group III & 1.78 & 0.365 \\
& Group IV & -1.00 & 0.609 \\
Group III & Group V & -6.01 & 0.003 \\
& Group IV & -2.77 & 0.160 \\
Group IV & Group V & -7.78 & 0.000 \\
\hline
\end{tabular}

The (group V) were statistically significant compared to other groups $(p<0.05)$

enamel surface. ${ }^{18}$ To obtain a good bonding strength, some authors suggested using new methods for enamel treatment, ${ }^{19-21}$ with preserving the maximum dental tissue. Enamel conditioning with air abrasion was proposed as a conservative conditioning technique aiming to create retentive microscopic gaps with a depth of 5-10 microns, which allowed the bonding agents to penetrate the enamel and obtain mechanical retention, forming a hybrid layer. ${ }^{22}$

Reynolds and Osorio et al., noted that a bond strength of 6-8 MPa is sufficient and necessary. ${ }^{23}$ However, all recent studies have shown higher values for bond strength of resin after enamel conditioning with acid etching. ${ }^{18,24}$
With the advancement of laser and being involved into different domains of dentistry, the researchers began to examine its effectiveness as an alternative choice to the traditional preparation techniques and its relationship with the bond strength of different bonding generations. The results of these studies were varied..$^{10}$

The Er:YAG laser mechanism focuses on energy absorption by water molecules found in hard dental tissues, and this method of conditioning increases enamel resistance to acids and reduces its dissolution. ${ }^{25,26}$

On the basis of the results of this study, all of the enamel conditioning methods have showed high bond strength values to resin cement with enamel surfaces, with a noticeable superiority of 
the (group V) Er:YAG laser followed by the acid etching technique, which showed the highest bond strength mean (27.05 MPa). The observed differences between group $V$ and the other groups were statistically significant.

The observed significant superiority of the Er:YAG laser followed by the acid etching technique may be due to a combination of exposure to Er:YAG and the etching with $37 \%$ phosphoric acid, which may create a porous surface and a honeycomb-like etching pattern, which enhances the penetration of the bond system and increases the bonding surface space, giving a better bonding.

The results of this study corresponded with the study of Sasaki et al., ${ }^{24}$ which found statistically significant differences between the Er:YAG laser followed by the acid etching group (11.7 MPa), and the acid etching group (8.2 MPa), knowing that the bond strength values in both groups were higher in this study. We also corresponded with the study of Sallam and Arnout. ${ }^{21}$

While current results did not coincide with Martínez-Insua et al., ${ }^{9}$ Dilber and Ozturk, ${ }^{11}$ and Sfondrini et al. ${ }^{2}$ This may be due to the lack of the combination of the Er:YAG laser and the acid etching that removes the laser-affected layer. In addition, the differences in the laser parameters were used to treat the enamel surfaces.

Er:YAG laser is a promising technique in dental practice because of its benefits such as increasing the bond strength and hence reduction of the recurrent caries. However, its effects on the teeth structure are still not fully explained, especially in regarding to surface morphology and the parameters of the laser device to be used. Therefore, further clinical researches are required on its role in the prevention of caries and its long-term impact on bonding.

\section{Conclusion}

The combination of the Er:YAG laser and the acid etching enhances the bond strength of resin cement with the enamel, and gave the best results with a significant differences compared to the other groups.

\section{References}

1. Alavi S, Birang R, et al. Shear bond strength of orthodontic brackets after acid-etched and erbium-doped yttrium aluminum garnet laseretched. Dent Res J 2014;11(3):321-326.

2. Sfondrini $M, C$ alderoni $G$, et al. Is laser conditioning a valid alternative to conventional etching for aesthetic brackets. Eur J Paediatr Dent 2018;19:61-66. DOI: 10.1007/s40368-017-0321-9.

3. Giannini M, Makishi P, et al. Self-etch adhesive systems: a literature review. Braz Dent J 2015;26(1):3-10. DOI: 10.1590/01036440201302442.

4. Bevilacqua L, Cadenaro M, et al. Influence of air abrasion and etching on enamel and adaptation of a dental sealant. Eur J Paediatr Dent 2007;8(1):25-30.

5. Van Meerbeek B, Van Landuyt K, et al. Technique-sensitivity of contemporary adhesives. Dent Mater J 2005;24(1):1-13. DOI: 10.4012/ dmj.24.1.

6. Kim M-E, Jeoung D-J, et al. Effects of water flow on dental hard tissue ablation using Er: YAG laser. J Clin Laser Med Surg 2003;21(3):139-144. DOI: 10.1089/104454703321895581.
7. Bertrand M-F, Brulat N, et al. Er: YAG laser cavity preparation and semidirect composite resin restoration: a microleakage study. Photomed Laser Surg 2008;26(5):473-477. DOI: 10.1089/pho.2007.2182.

8. Hossain M, Nakamura Y, et al. Ablation depths and morphological changes in human enamel and dentin after Er: YAG laser irradiation with or without water mist. J Clin Laser Med Surg 1999;17(3):105-109. DOI: 10.1089/clm.1999.17.105.

9. Martínez-Insua A, da Silva Dominguez L, et al. Differences in bonding to acid-etched or Er:YAG-laser-treated enamel and dentin surfaces. J Prosthet Dent 2000;84(3):280-288. DOI: 10.1067/mpr.2000.108600.

10. Bevilácqua FM, Zezell DM, et al. Fluoride uptake and acid resistance of enamel irradiated with Er: YAG laser. Lasers Med Sci 2008;23(2): 141-147. DOI: 10.1007/s10103-007-0466-6.

11. Dilber E, Ozturk AN. Bond strength of porcelain bonded to enamel and dentin surfaces prepared with different surface treatments. J Adhes 2015;91(8):651-662. DOI: 10.1080/00218464.2014.959937.

12. Gerbo LR, Lacefield WR, et al. The effect of enamel preparation on the tensile bond strength of orthodontic composite resin. Angle Orthod 1992;62(4):275-281.

13. Canay Ş, Kocadereli I, et al. The effect of enamel air abrasion on the retention of bonded metallic orthodontic brackets. Am J Orthod Dentofacial Orthop 2000;117(1):15-19. DOI: 10.1016/S08895406(00)70243-5.

14. Lasmar M, Reher V, et al. Enamel demineralization and bracket bond strength when etching with acid and/or Er: YAG laser. Aust Dent J 2012;57(2):190-195. DOI: 10.1111/j.1834-7819.2012.01679.x.

15. Shah DD, Chandak M, et al. Comparing Shear Bond Strength of Two Step vs One Step B onding Agents on Ground Enamel and Dentin: An in vitro Study. Int J Exp Dent Sci 2014;3(1):1-3.

16. Farias-Neto A, Gomes EMdCF, et al. Esthetic Rehabilitation of the smile with no-prep porcelain laminates and partial veneers. Case Rep Dent 2015;2015:1-6. DOI: 10.1155/2015/452765.

17. ZARoNe F, LeoNe R, et al. No-preparation ceramic veneers: a systematic review. J Osseointegration 2018;10(1):17-22.

18. Mehdi S, Mano M-C, et al. Air abrasion of enamel. Orthod Fr 2009;80:179-192. DOI: 10.1051/orthodfr/2009012.

19. Ellis RW, Latta MA, et al. Effect of air abrasion and acid etching on sealant retention: an in vitro study. Pediatr Dent 1999;21(6):316-319.

20. Moslemi M, Erfanparast L, et al. The effect of Er, Cr: YSGG laser and air abrasion on shear bond strength of a fissure sealant to enamel. J Am Dent Assoc 2010;141(2):157-161. DOI: 10.14219/jada.archive.2010.0133.

21. Sallam RA, Arnout EA. Effect of Er: YAG laser etching on shear bond strength of orthodontic bracket. Saudi Med J 2018;39(9):922-927. DOI: 10.15537/smj.2018.9.22793.

22. Sharma S, Hegde MN, et al. Clinical and Radiographic Comparison of Conventional and Minimal Invasive Method of Cavity Preparation in Mandibular Molars. Indian J Public Health Res Dev 2018;9(6):170-175. DOI: 10.5958/0976-5506.2018.00544.2.

23. Osorio $\mathrm{R}$, Toledano $\mathrm{M}$, et al. Bracket bonding with 15-or 60-second etching and adhesive remaining on enamel after debonding. Angle Orthod 1999;69(1):45-48.

24. Sasaki LH, Lobo PD, et al. Tensile bond strength and SEM analysis of enamel etched with Er:YAG laser and phosphoric acid: a comparative study in vitro. Braz Dent J 2008;19(1):57-61.

25. Cecchini RCM, Zezell DM, et al. Effect of Er: YAG laser on enamel acid resistance: Morphlogical and atomic spectrometry analysis. Lasers Surg Med 2005;37(5):366-372. DOI: 10.1002/Ism.20247.

26. Castellan CS, Luiz AC, et al. In vitro evaluation of enamel demineralization after Er: YAG and Nd: YAG laser irradiation on primary teeth. Photomed Laser Surg 2007;25(2):85-90. DOI: 10.1089/ pho.2006.2043. 